\title{
Lipid-soluble cigarette smoking particles induce expression of inflammatory and extracellular- matrix-related genes in rat cerebral arteries
}

\author{
Petter Vikman \\ Cang-Bao Xu \\ Lars Edvinsson \\ Department of Clinical Sciences, \\ Experimental Vascular Research, \\ Lund, Sweden
}

\begin{abstract}
Aims: Cigarette smoking is one of the strongest risk factors for stroke. However, the underlying molecular mechanisms that smoke leads to the pathogenesis of stroke are incompletely understood.

Methods: Dimethyl sulfoxide (DMSO)-soluble (lipid-soluble) cigarette smoking particles (DSP) were extracted from cigarette smoke $\left(0.8 \mathrm{mg}\right.$ nicotine per cigarette; Marlboro $\left.{ }^{\circledR}\right)$. Rat cerebral arteries were isolated and organ cultured in the presence of DSP $(0.2 \mu \mathrm{l} / \mathrm{ml}$, equivalent to the plasma level in smokers) for $24 \mathrm{~h}$. The expression of matrix metalloproteinase 9 and 13 (MMP9 and MMP13), angiotensin receptor 1 and $2\left(\mathrm{AT}_{1}\right.$ and $\left.\mathrm{AT}_{2}\right)$, interleukin 6 and inducible nitric oxide synthase (iNOS) were investigated at mRNA level by real-time PCR and/or at protein level by immunohistochemistry. In addition, the activity of three mitogen-activated protein kinases (p38, ERK 1/2 and SAPK/JNK) and their downstream transcription factors (ATF-2, Elk-1 and c-Jun) were examined.

Results: We observed that compared with control (DMSO-treated cerebral arteries), the cerebral arteries treated by DSP exhibited enhanced expression of MMP13 and AT 1 receptors, but not of $\mathrm{AT}_{2}$ receptors, at both mRNA and protein levels, suggesting that a transcriptional mechanism is most likely involved in the DSP effects. This is further supported by the findings that DSP induced phosphorylation of $\mathrm{p} 38$ mitogen-activated protein kinases inflammatory signal protein in parallel with activation of its downstream transcription factor ATF-2 and Elk-1. However, ERK 1/2 and $\mathrm{SAPK} / \mathrm{JNK}$ activities were markedly expressed in the control (organ culture per se with DMSO), and DSP failed to further enhance the activation of ERK $1 / 2$ and SAPK/JNK in the cerebral arteries. Conclusions: DSP induces cerebral vessel inflammation with activation of p38 MAPK inflammatory signal and the downstream transcriptional factors (ATF-2 and Elk-1) in parallel with enhanced extracellular-matrix-related gene transcription and increased $\mathrm{AT}_{1}$ receptor expression in the cerebral arteries, which are key events in stroke pathogenesis.
\end{abstract}

Keywords: cigarette smoking, vascular inflammation, signal transduction, extracellular matrix, MMP, stroke

\section{Introduction}

Cigarette smoke is well-known to increase risk for stroke. ${ }^{1}$ An epidemiologic follow-up study shows that the risk was significantly increased in smokers for all strokes including a further increased risk in ischemic stroke among cigarette-smoking women with a cigarette-smoking spouse. ${ }^{2}$ Cigarette smoke leads to an increased risk of aneurismal subarachnoid hemorrhage (SAH). ${ }^{3}$ Smoking is associated with increased fibrinogen concentration, ${ }^{4}$ enhanced platelet agglutinability ${ }^{5}$ and reduced fibrinolytic activity, ${ }^{6}$ as well as with increased cerebrovascular constriction. ${ }^{7}$ The molecular mechanisms to explain how smoking increases the risk for both ischemic and hemorrhage strokes are still elusive.

Mitogen-activated protein kinases (MAPK) are key intracellular inflammatory signal molecules that can be activated by inflammatory cytokines, growth factors, and stress.
Correspondence: Cang-Bao Xu Department of Clinical Sciences, Experimental Vascular Research, BMC A I 3, 22I 84, Lund, Sweden Tel +46462220825

Fax +4646222016

Email cang-bao.xu@med.lu.se 
These kinases are known to be involved in upregulation of matrix metalloproteinases (MMP) transcription in the smooth muscle cells ${ }^{8}$ and enhanced expression of vascular G-protein coupled receptors (GPCR) such as angiotensin II receptor 1 $\left(\mathrm{AT}_{1}\right)$ and contractile endothelin type $\mathrm{B}\left(\mathrm{ET}_{\mathrm{B}}\right)$ receptors in the cerebral arteries in stroke. ${ }^{9}$ The present study was designed to test the hypothesis that dimethyl sulfoxide (DMSO)-soluble (lipid-soluble) cigarette smoke particles (DSP) may induce activation of the MAPK-mediated inflammatory signal pathways, the enhanced expression of extracellular-matrix-related genes and upregulation of AT receptors in the cerebral arteries. These are key events that have been seen in cerebral ischemic stroke in man, ${ }^{10}$ in experimental middle cerebral artery occlusion ${ }^{9,11,12}$ and in SAH. ${ }^{13,14}$

Previously, we have used an in vitro organ culture of cerebral artery model as a surrogate for studying cerebrovascular receptor changes in stroke and observed that ERK 1/2 MAPK is activated during the organ culture and this occurred in parallel with enhanced contractile $\mathrm{ET}_{\mathrm{B}}$ receptor expression in the cerebral arteries. ${ }^{15}$ In the mesenteric arteries, organ culture in the presence of DSP induced further activation of MAPK-mediated intracellular inflammatory signaling and additional enhancement of transcription for contractile $\mathrm{ET}_{\mathrm{B}}$ receptors in the smooth muscle cells. ${ }^{16}$ Furthermore, we have demonstrated that a transcriptional mechanism dependent on activation of MAPK-mediated inflammatory signaling is involved in the DSP toxic effects on the mesenteric arteries. ${ }^{16}$ By using the same organ culture model, the present study demonstrates a similar mechanism that might be involved in smoke-induced cerebral vessel dysfunctions and damage, key events in pathogenesis of stroke. This is based on our findings that organ culture of cerebral arteries in presence of DSP can also induce activation of p38 MAPK inflammatory signaling and its downstream transcriptional factors (ATF-2 and Elk-1), enhance expression of extracellular-matrix-related genes (MMP9 and MMP13) and increase vascular AT 1 receptor expression at both mRNA and protein levels.

\section{Materials and methods}

\section{DMSO-lipid soluble cigarette smoking}

\section{particles extraction}

Three cigarettes $\left(0.8 \mathrm{mg}\right.$ nicotine per cigarette; Marlboro ${ }^{\circledR}$, Philip Morris USA, Pittsburgh, PA, USA) were "smoked" by a water aspirator, and the smoke directed through a cotton wool filter. The cigarette smoke particles, retained in the filter, were dissolved in $1 \mathrm{ml}$ DMSO for detailed description of the procedure see Grandström and colleagues. ${ }^{17}$ Preliminary tests revealed no effects of water-soluble cigarette smoke particles and thus attention was directed to the DSP preparation. The dose chose of DSP was based on our previous study. ${ }^{16} 0.2 \mu \mathrm{l} /$ $\mathrm{ml}$ of DSP (containing $20 \mathrm{ng} / \mathrm{ml}$ of nicotine), equivalent to the plasma level in smokers, was used. ${ }^{18,16}$

\section{Vessel preparation}

Male Sprague Dawley rats weighing 250-300 g were euthanized by $\mathrm{CO}_{2}$, the middle cerebral artery (MCA) and basilar artery (BA) were dissected out. The arteries were either used directly ( 0 hours) or were placed for $24 \mathrm{~h}$ in $5 \mathrm{ml}$ of Dulbecco's Modified Eagle Medium (DMEM) in an incubator set to $37{ }^{\circ} \mathrm{C}$ containing $5 \% \mathrm{CO}_{2}$. Prior to incubation $1 \mu \mathrm{l}$ of DMSO (control) or DSP was mixed with $5 \mathrm{ml}$ of DMEM (without DMSO or saline instead gave similar results; data not shown). The cerebral vessel segments were then frozen instantaneously by the use of a freezer spray (Shandon, Houston, TX, USA) and stored at $-80^{\circ} \mathrm{C}$ until RNA preparation took place or used for immunohistochemistry (see below).

\section{RNA isolation}

Following the manufacturer's protocols, total RNA preparations were obtained using the TRIzol ${ }^{\circledR}$ RNA isolation kit (Invitrogen, Carlsbad, CA, USA). Briefly, the arteries were homogenized using TissueLyser (VWR, Stockholm, Sweden). The homogenates were then suspended in $1 \mathrm{ml}$ of Trizol (Invitrogen, Stockholm, Sweden) and were centrifuged at 12,000 RPM at $4{ }^{\circ} \mathrm{C}$ for $15 \mathrm{~min}$ to remove debris. The supernatant was transferred to a different tube and the rest was discarded. The samples were then incubated for $5 \mathrm{~min}$ at room temperatures and flicked every $30 \mathrm{sec}$. To remove all traces of phenol, $300 \mu$ l of chloroform was added and the samples were mixed by inversion. Then, the samples were incubated at room temperature again for 2-3 $\mathrm{min}$, followed by $15 \mathrm{~min}$ centrifugation at $12,000 \mathrm{~g}$ at $4{ }^{\circ} \mathrm{C}$. The upper phase was collected and the rest was discarded. Chloroform was again added to remove all traces of phenol and the samples were spun at $12000 \mathrm{~g}$ at $4{ }^{\circ} \mathrm{C}$ for $5 \mathrm{~min}$. The RNA was precipitated by addition of an equal amount of isopropanol and was incubated overnight at $-80{ }^{\circ} \mathrm{C}$. The RNA was subsequently pelleted at $12,000 \mathrm{~g}$ for $20 \mathrm{~min}$ at $4{ }^{\circ} \mathrm{C}$. The RNA was re suspended in $10 \mu \mathrm{l}$ of nuclease free water, the 260/280 values being measured using a GeneQuant Pro spectrophotometer (Amersham Pharmacia Biotech, Uppsala, Sweden).

\section{Real-time PCR investigation}

The cDNA for the real-time polymerase chain reactions (PCR) were created in $40 \mu \mathrm{l}$ reactions using SuperScript ${ }^{\circledR}$ III in accordance with the manufacturer's instructions (Perkin-Elmer, Applied Biosystems, Foster City, CA, USA). One $\mu \mathrm{g}$ of RNA 
was used in each reaction. The subsequent real-time PCR was performed in a GeneAmp 5700 Sequence Detection system (Perkin-Elmer, Applied Biosystems) using the GeneAmp SYBR $^{\circledR}$ Green kit (Perkin-Elmer, Applied Biosystems) with a $25 \mu \mathrm{l}$ reaction volume and $1 \mu \mathrm{l}$ of the above mentioned cDNA serving as a template. Each reaction was performed in duplicate and was run for 40 cycles. $\beta$-actin and elongation factor 1 (EF-1) were used as housekeeping genes. The gene expressions were normalized versus the housekeeping genes to account for differences in the starting material and in the cDNA reaction efficiency; for a more detailed account of the procedure see Hansen-Schwartz and colleagues. ${ }^{19}$ Each primer pair was specific for the genes of interest (Table 1).

\section{DAB immunohistochemistry}

The rat MCA was dissected out, treated as described above and placed in Tissue TEK (Gibco, Carlsbad, CA, USA), frozen and subsequently sectioned into $10 \mu \mathrm{m}$ thick slices in a calibrated Microm HM500 M cryostat (Microm, Walldorf, Germany). The primary antibodies used were rabbit antiphospho p38 (\#4631; Cell Signaling Technology Inc., Danvers, MA, USA), rabbit anti-phospho ERK 1/2 MAPK (\#4376; Cell Signaling Technology Inc.), rabbit anti-phospho SAPK/JNK (\#9251; Cell Signaling Technology Inc.) rabbit anti-phospho ATF-2 (\#9221; Cell Signaling Technology Inc.), rabbit anti-phospho Elk-1 (\#9181; Cell Signaling Technology Inc.) and rabbit anti-phospho c-Jun (\#9261; Cell Signaling Technology Inc.) each diluted 1:50. The secondary antibodies used were biotin-conjugated goat anti-rabbit antibodies
(111-065-003; Jackson ImmunoResearch, Newmarket, Suffolk, UK) diluted 1:100. All dilutions were with phosphate buffer saline (PBS) containing $0.3 \%$ Triton-X100 and $5 \%$ fetal calf serum. The Vectastain ABC kit (Vector Laboratories, Burlingame, CA, USA) together with DAB substrate (Rockland Immunochemicals Inc., Gilbertsville, PA, USA) was used for detection in accordance with the manufacturers' instructions. Pictures were taken at $40 \times$ magnification. Secondary antibodies alone served as a negative control.

After the arterial segments had been incubated in the presence of either DSP $0.2 \mu \mathrm{l} / \mathrm{ml}$ or DMSO $0.2 \mu \mathrm{l} / \mathrm{ml}$ (control) for $24 \mathrm{~h}$, they were cut into sections and stained with the DAB methods. For each vessel, six pre-directed sections were assessed according to the previously published protocol with slight modifications ${ }^{16,20}$ The DAB intensity was measured at six pre-directed preset areas in the smooth muscle cell layers. The mean intensity was obtained from four vessels. The DAB intensity measurement was rechecked by experienced senior co-workers.

\section{Fluorescence immunohistochemistry}

The rat MCA was dissected out, treated as described above and placed in Tissue TEK (Gibco), frozen and subsequently sectioned into $10 \mu \mathrm{m}$ thick slices in a calibrated Microm HM500M cryostat (Microm). The primary antibodies were mouse anti-MMP13 (ab3208; Abcam, Cambridge, MA, USA) diluted 1:100, rabbit anti-human AT1 (sc-1173; Santa Cruz Biotechnology Inc., Santa Cruz, CA, USA) diluted 1:100, rabbit anti-human AT2 (sc-9040; Santa Cruz Biotechnology Inc).

Table I Gene-specific primer sequences and accession numbers

\begin{tabular}{|c|c|c|c|}
\hline Gene name & Abbreviation & Accession number & Primer sequence \\
\hline Beta-actin & $\beta$-actin & NM-03II44 & $\begin{array}{l}\text { gtagccatccaggctgtgttg } \\
\text { tgccagtggtacgaccagag }\end{array}$ \\
\hline Elongating factor I & EF-I & NM-I 75838 & $\begin{array}{l}\text { gcaagcccatgtgtgttgaa } \\
\text { tgatgacacccacagcaactg }\end{array}$ \\
\hline Interleukin 6 & IL6 & NM-0I 2589 & $\begin{array}{l}\text { aagagacttccagccagttgcc } \\
\text { actggtctgttgtgggtggtatc }\end{array}$ \\
\hline Inducible no synthase & iNOS & NM-0I26II & $\begin{array}{l}\text { caatggcttgaggcagaagc } \\
\text { gccacctcggatatctcttgc }\end{array}$ \\
\hline Matrix metalloproteinase 9 & MMP9 & NM-03I055 & $\begin{array}{l}\text { aagccttggtgtggcacgac } \\
\text { tggaaatacgcagggtttgc }\end{array}$ \\
\hline Matrix metalloproteinase 13 & MMPI3 & $M 60616$ & $\begin{array}{l}\text { tctgcaccctcagcaggttg } \\
\text { catgaggtctcgggatggatg }\end{array}$ \\
\hline Angiotensin II receptor I & $\mathrm{AT}_{1}$ & NM-030985 & $\begin{array}{l}\text { ggtggagtgacaggttcaaagc } \\
\text { agggtgaatggtcctttggtc }\end{array}$ \\
\hline Angiotensin II receptor 2 & $\mathrm{AT}_{2}$ & U01908 & $\begin{array}{l}\text { tctgttagtgggatgcatgtaatca } \\
\text { tgtgggcctccaaaccatt }\end{array}$ \\
\hline
\end{tabular}


diluted 1:100. All dilutions were with PBS containing 10\% fetal calf serum. The secondary antibodies were donkey antimouse Cy'M 5 conjugated (715-175-150; Jackson ImmunoResearch Inc.) 1:100 and donkey antirabbit Cy ${ }^{\mathrm{TM}} 3$ conjugated (711-165-152; Jackson ImmunoResearch Inc.) diluted 1:100 with PBS containing 10\% fetal calf serum.

\section{Picture analysis}

We investigated the fluorescence or DAB intensity using ImageJ v1.41 software (downloaded from http://rsb.info. nih.gov/ij/). The mean intensity based on measurements in six parts of each segment is reported. The mean values of each vessel were used in calculating the mean at each point in time or treatment.

\section{Statistics}

Differences were investigated using the Mann-Whitney $U$ test and $p<0.05$ being considered statistically significant.

\section{Results}

\section{mRNA expression studies}

Gene expression was investigated by a real-time PCR in fresh MCA and BA following $24 \mathrm{~h}$ of organ culture using either
DMSO or DSP. EF-1 and $\beta$-actin were used to normalize the results. Both housekeeping genes gave the same result after normalization in both MCA and BA. The results are presented in terms of the mean regulation \pm SEM as compared with 0 hour of incubation. Il-6, iNOS, MMP9, and MMP13 were investigated because of results from previous microarray studies. ${ }^{10,21}$ IL-6 and iNOS were significantly upregulated after $24 \mathrm{~h}$ of culture with vehicle, while we did not observe a further enhancement by DSP treatment. However, MMP9 and MMP13 did not change after $24 \mathrm{~h}$ of organ culture in presence of vehicle, but they were significantly upregulated in the DSP-treated arteries (Figure 1). In addition, DSP caused a significant enhancement of vascular $\mathrm{AT}_{1}$ receptor mRNA expression as compared with that of the DMSO-treated cerebral arteries (Figure 2), while this was not seen for $\mathrm{AT}_{2}$ receptor mRNA expression.

\section{Signal transduction}

Organ culture per se (without DMSO vehicle) has been studied before. ${ }^{15}$ Here, by using immunohistochemistry, we examined activation (phosphorylated) of intracellular signal molecule p38, ERK 1/2, SAPK/JNK and the downstream transcription factors ATF-2, Elk-1, and c-Jun. Compared with fresh arteries, the levels of pERK $1 / 2$ and $\mathrm{pSAPK} / \mathrm{JNK}$ were
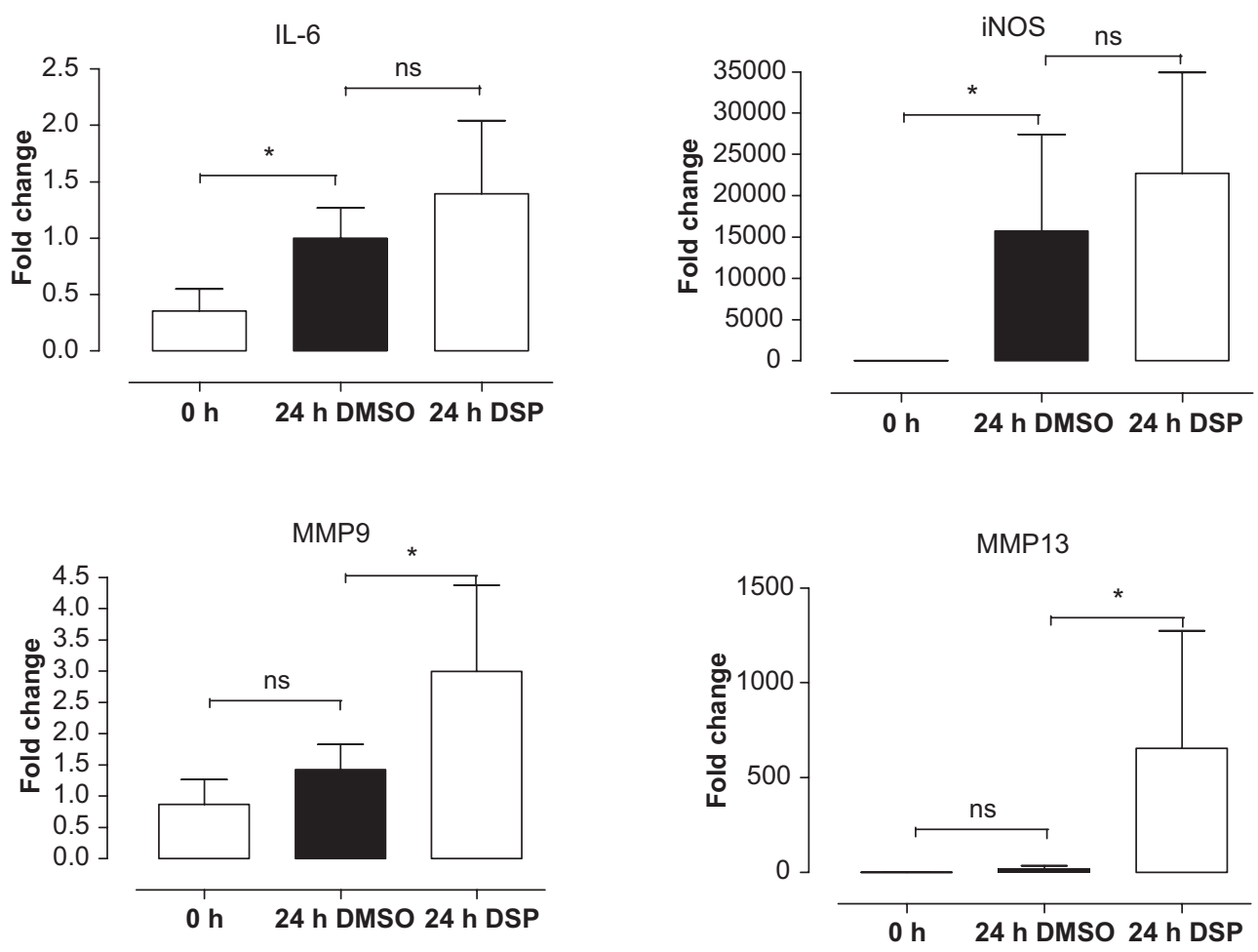

Figure I The expression of the inflammatory genes tended to be greater in the cerebral arteries treated with DSP than in the cerebral arteries treated with DMSO control. There was a significant upregulation of the extracellular-matrix-related genes (MMP9 and MMPI3) in the DSP group, compared with DMSO control.The cerebral arteries have been organ cultured for 24 hours in the presence of DSP or DMSO (control).

Notes: Data presented as mean \pm SEM, $n=4 ;{ }^{*} p<0.05$.

Abbreviations: DMSO, dimethyl sulfoxide; DSP, cigarette smoke particles; MMP, matrix metalloproteinase; ns, not significant. 

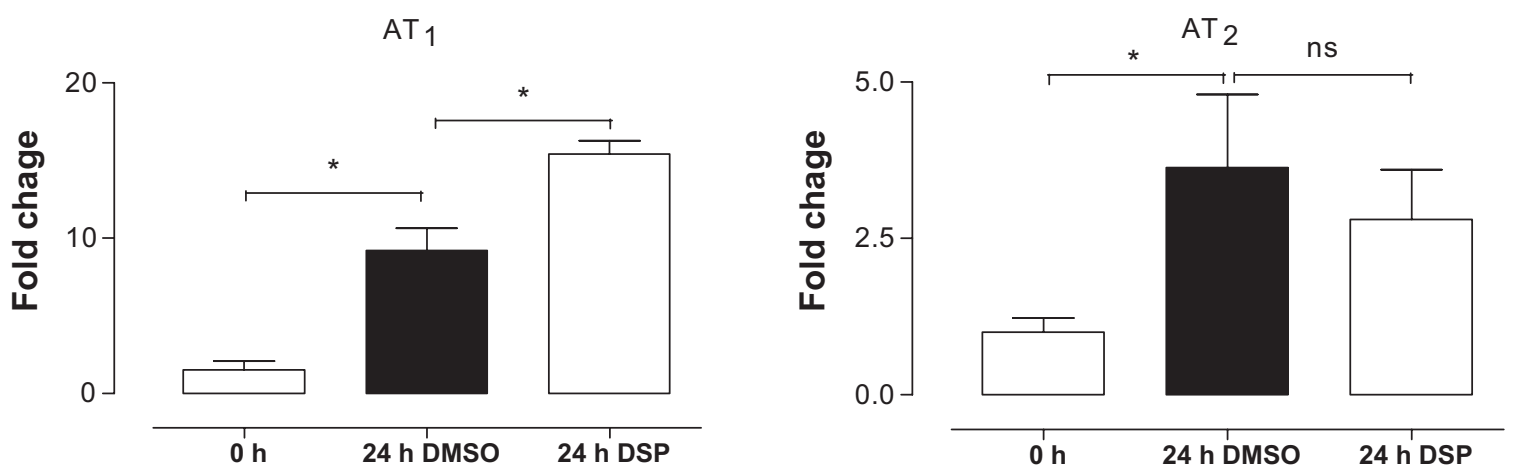

Figure 2 The expression of angiotensin II receptors in the cerebral arteries following organ culture with DSP or DMSO (control), there was a significant upregulation of the AT, receptors induced by DSP compared with DMSO.

Notes: Data presented as mean \pm SEM, $n=4 ;{ }^{*} p<0.05$.

Abbreviations: AT, angiotensin receptor; DMSO, dimethyl sulfoxide; DSP, cigarette smoke particles; ns, not significant.

elevated both in DMSO- and DSP-treated arteries, however, there was no significant difference between the DMSO and DSP groups (Table 2). Activation of p38 was not seen in the fresh arteries ( 0 hour incubation) and there was only a slight increase in p38 activation after $24 \mathrm{~h}$ of culture in presence of DMSO. Interestingly, the DSP-treated arteries showed a significant activation of $\mathrm{p} 38$, compared with both the fresh and DMSO-treated artery segments (Table 2; Figure 3).

The transcription factor ATF-2 activation showed a pattern similar to that of $\mathrm{p} 38$; there was no pATF-2 in fresh arteries whereas a distinct activation was evident in arteries incubated for $24 \mathrm{~h}$ together with DSP (Figure 3). In addition, DSP induced a strong activation of transcriptional factor Elk-1 (Figure 3) in the cerebral arteries. The transcription factor c-Jun was activated at same degree both in the DMSOtreated and in the DSP-treated arteries (Table 2).

\section{MMPI 3 and AT receptor expressions}

The protein expression of MMP13 and AT receptors in the cerebral arteries was investigated by using immunohistochemistry. We observed these proteins were expressed mostly in the smooth muscle cells. An increase in the amounts of MMP13 protein in the cerebral arteries (Figure 4) was consistent with the mRNA expression findings. The amounts of $\mathrm{AT}_{1}$ receptor protein was also investigated due to the increased mRNA expression found. Compared with fresh arteries, the $\mathrm{AT}_{1}$ receptor protein was elevated in DMSO group and further increased by DSP. But, this was not seen for the expression of $\mathrm{AT}_{2}$ receptors after DSP treatment (Figure 4).

\section{Discussion}

We have for the first time demonstrated that in cerebral arteries, lipid-soluble cigarette smoke particles (DSP) induced activation of the p38 MAPK intracellular inflammatory signaling and phosphorylation of its downstream transcriptional factors (ATF-2 and Elk-1), enhanced expression of extracellular-matrix-related gene MMP13 and upregulation of vascular $\mathrm{AT}_{1}$ receptors at both mRNA and protein levels. Our findings suggest that the p38 MAPK-mediated inflammatory signaling is most likely involved in the DSP toxic effects on the cerebral arteries. In agreement with this, we have previously observed that DSP could activate the MAPK inflammatory signaling-mediated transcriptional mechanisms and subsequently resulted in upregulation of contractile $\mathrm{ET}_{\mathrm{B}}$ receptor expression in the smooth muscle cells of mesenteric arteries. ${ }^{16}$ In addition, we have linked DSP-induced activation of p38 pathways to the $\mathrm{ET}_{\mathrm{B}}$ upregulation by specific inhibition of p38 activity, which demonstrates that $\mathrm{p} 38$ MAPK-mediated transcriptional mechanisms are involved in the $\mathrm{ET}_{\mathrm{B}}$ upegulation. ${ }^{16}$ In the present study, DSP may induce the increased expression of MMPs via similar mechanisms through phosphorylation of p38 and activation of its downstream transcription factors (ATF-2 or ElK-1).

Table 2 Phosphorylation of intracellular signal proteins induced by DSP

\begin{tabular}{llll}
\hline & Fresh & DMSO-treated & DSP-treated \\
\hline P-P38 & $\mathrm{I} \pm 0.26$ & $1.15 \pm 0.38$ & $\mathrm{I} .8 \mathrm{I} \pm 0.26^{*}$ \\
P-ERK I/2 & $\mathrm{I} \pm 0.18$ & $\mathrm{I} .58 \pm 0.13$ & $\mathrm{I} .83 \pm 0.40$ \\
P-SAPK/JNK & $\mathrm{I} \pm 0.03$ & $\mathrm{I} .5 \mathrm{I} \pm 0.34$ & $\mathrm{I} .79 \pm 0.09$ \\
P-ATF-2 & $\mathrm{I} \pm 0.12$ & $\mathrm{I} .14 \pm 0.09$ & $\mathrm{I} .6 \mathrm{I} \pm 0.37^{*}$ \\
P-Elk-I & $\mathrm{I} \pm 0.19$ & $\mathrm{I} .08 \pm 0.54$ & $2.18 \pm 0.09^{*}$ \\
P-c-Jun & $\mathrm{I} \pm 0.49$ & $\mathrm{I} .8 \mathrm{I} \pm 0.25$ & $\mathrm{I} .88 \pm 0.27$ \\
\hline
\end{tabular}

Notes: Data presented as mean \pm SEM, $n=4 ;{ }^{*} p<0.05$ when comparing DSP with DMSO control.

Abbreviations: DMSO, dimethyl sulfoxide; DSP, cigarette smoke particles. 


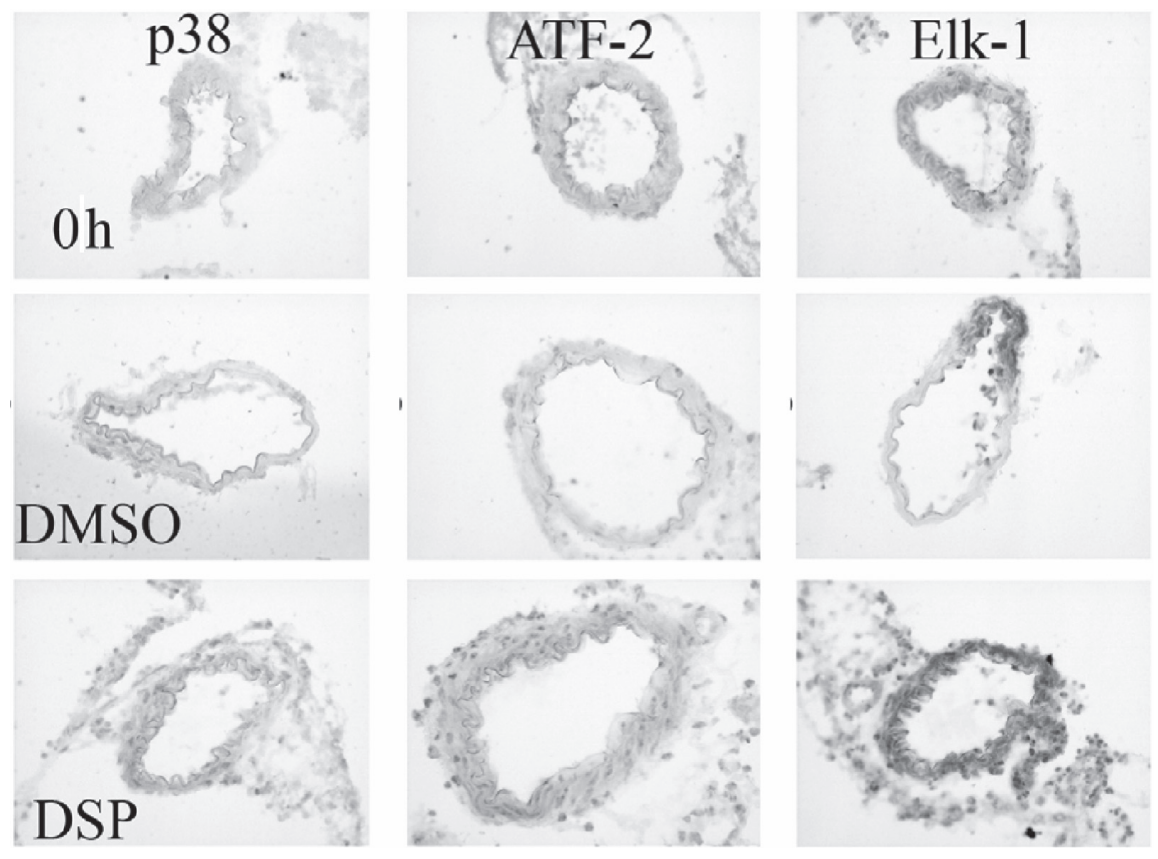

Figure 3 No p38 phosphorylation was found in the fresh cerebral arteries, while a slight increase was obtained in the cerebral arteries treated with DMSO and a strong activation in the cerebral arteries treated with DSP, ATF-2 and Elk-I showed the same pattern as the p38 phosphorylation. However, phosphorylation of Elk-I was also seen in the fresh cerebral arteries.

Abbreviations: DMSO, dimethyl sulfoxide; DSP, cigarette smoke particles.

We have studied the time course of DSP and the DSP dose-dependent effects previously ${ }^{8,16,22}$ The results show that DSP dose-dependently triggers the arterial smooth muscle cells and induces effects starting at concentration $0.1 \mu \mathrm{l} / \mathrm{ml}$ and reaching its maximal effect at $0.2 \mu 1 / \mathrm{ml}$ and declining at $0.4 \mu \mathrm{l} / \mathrm{ml}$. The time course study shows that DSP induces activation (phosphorylation) of p38 within $3 \mathrm{~h}$ and further increasing the activation during $24 \mathrm{~h}$. This is associated with upregulation of $\mathrm{ET}_{\mathrm{B}}$ receptor protein expression at $6 \mathrm{~h}$, assessed by Western blot in the arterial smooth muscle cells. The $\mathrm{ET}_{\mathrm{B}}$ receptor upregulation is further increased up to $24 \mathrm{~h}$ at functional and protein levels (contractile response and immunohistology). ${ }^{16}$ Based on above studies, we used DSP $0.2 \mu \mathrm{l} / \mathrm{ml}$ (containing $20 \mathrm{ng} / \mathrm{ml}$ of nicotine, equivalent to the plasma level in smokers) for the present study. ${ }^{18}$

Smoke is associated with increased risk of cerebral and cardiovascular diseases including stroke and myocardial infarction $^{1,6}$ So far, little is known about the signaling mechanisms of smoke-induced vascular dysfunction and damage. Studies have showed that smoke extracts ${ }^{23}$ and acrolein, ${ }^{24}$ a well known toxic substance in tobacco smoke, could stimulate phosphorylation of the $\mathrm{p} 38$ MAPK protein in the vascular cells. We investigated activation (phosphorylation) of MAPK and their downstream transcriptional factors in the cerebral arteries and showed that while ERK 1/2 and
SAPK/JNK activations were not seen in the fresh cerebral arteries, they were strongly activated by an organ culture per se with DMSO. Adding DSP did not further increase the activation of ERK $1 / 2$ and SAPK/JNK. The $\mathrm{p} 38$ was likewise not active in fresh arteries and the incubation of the cerebral arteries together with DMSO caused only a minor activation; the addition of DSP strongly augmented the activation of $\mathrm{p} 38$. The activation of c-Jun followed the pattern shown for SAPK/JNK and ERK 1/2, there being a strong activation in control cerebral arteries (treated with DMSO), but no further activation induced by DSP. ATF-2 and Elk-1, on the other hand, displayed only a minor activation in control cerebral arteries and DSP caused a strong activation of them. Thus, the present study demonstrates that DSP induces activation of the p38 MAPK inflammatory signaling and phosphorylation of its downstream transcription factors (ATF-2 and Elk-1). This might be associated with the increased mRNA expression for MPP9, MMP13 and $\mathrm{AT}_{1}$ receptors induced by DSP. However, ERK 1/2 and the SAPK/JNK MAPK activities were markedly increased in the control and DSP did not result in further increase in their activities (Table 2).

Inflammatory responses of cerebral blood vessels and increased MMP activity play key roles in cerebralvascular disease, particularly in formation of intracranial aneurysm that leads to stroke. Although inflammatory macrophages 
and lymphocytes infiltrate the aneurysm wall, a link between their presence and aneurysm growth with subsequent rupture is not completely understood. ${ }^{25}$ The present study, by using organ culture of cerebral arteries in the presence of lipid-soluble cigarette smoke particles, has for the first time demonstrated that in the cerebral arteries, lipid-soluble cigarette smoke particles induced activation of the p38 MAPK intracellular inflammatory signaling and phosphorylation of its downstream transcriptional factors (ATF-2 and Elk-1), enhanced the expression of extracellular-matrix-related gene MMP13 and upregulation of vascular $\mathrm{AT}_{1}$ receptors. Thus, organ culture of cerebral arteries in the presence of lipid-soluble cigarette smoke particles provides an ex vivo model of cerebral vessel inflammation, which can be used as a surrogate for studying cerebrovascular inflammation and the underlying molecular mechanisms involved.

MMP can degrade components of the arterial wall extracellular matrix and involve in the pathogenesis of cerebral aneurysm formation and rupture. Serum MMP9 levels increase in SAH patients and returns to the normal level by the day 12 of post-SAH. ${ }^{26}$ More importantly, local changes in metalloprotease activity in the cerebral vasculature are considered as a key event in cerebral aneurysm formation and rupture in $\mathrm{SAH} .{ }^{27}$ In the present study, we found a significant upregulation of the metalloproteinases MMP9 and MMP13. MMP9 has previously been seen in cerebral ischemia, ${ }^{28}$ and thought to be associated with breakdown of the blood-brain barrier. ${ }^{29}$ MMP13, on the other hand, has been found to participate in inflammatory responses. ${ }^{30}$ The increase in the amount of MMP13 protein present in the arterial walls following exposure to DSP suggests that there is a putative degradation of the basal lamina. This is supported by the observation that the smoke extracts may cause recruitment of the MMP secreting immune cells. ${ }^{28}$ The enhanced expression of MMPs might increase the inflammatory response in the arteries, alter the function of the blood-brain barrier and result in the influx of the inflammatory cells in smokers.

Cigarette smoke contains more than 4000 substances with many toxic chemicals that may cause vascular damage. We have studied the effects of DMSO-soluble (lipid-soluble), water-soluble cigarette smoke particles and nicotine per se on vasculature. ${ }^{16}$ Recently, heptane-soluble, DMSO-soluble and water-soluble cigarette smoke particles and their effects on G-protein coupled receptor expression were investigated (unpublished data). These results show that it is the lipidsoluble cigarette smoke particles, but not water soluble or
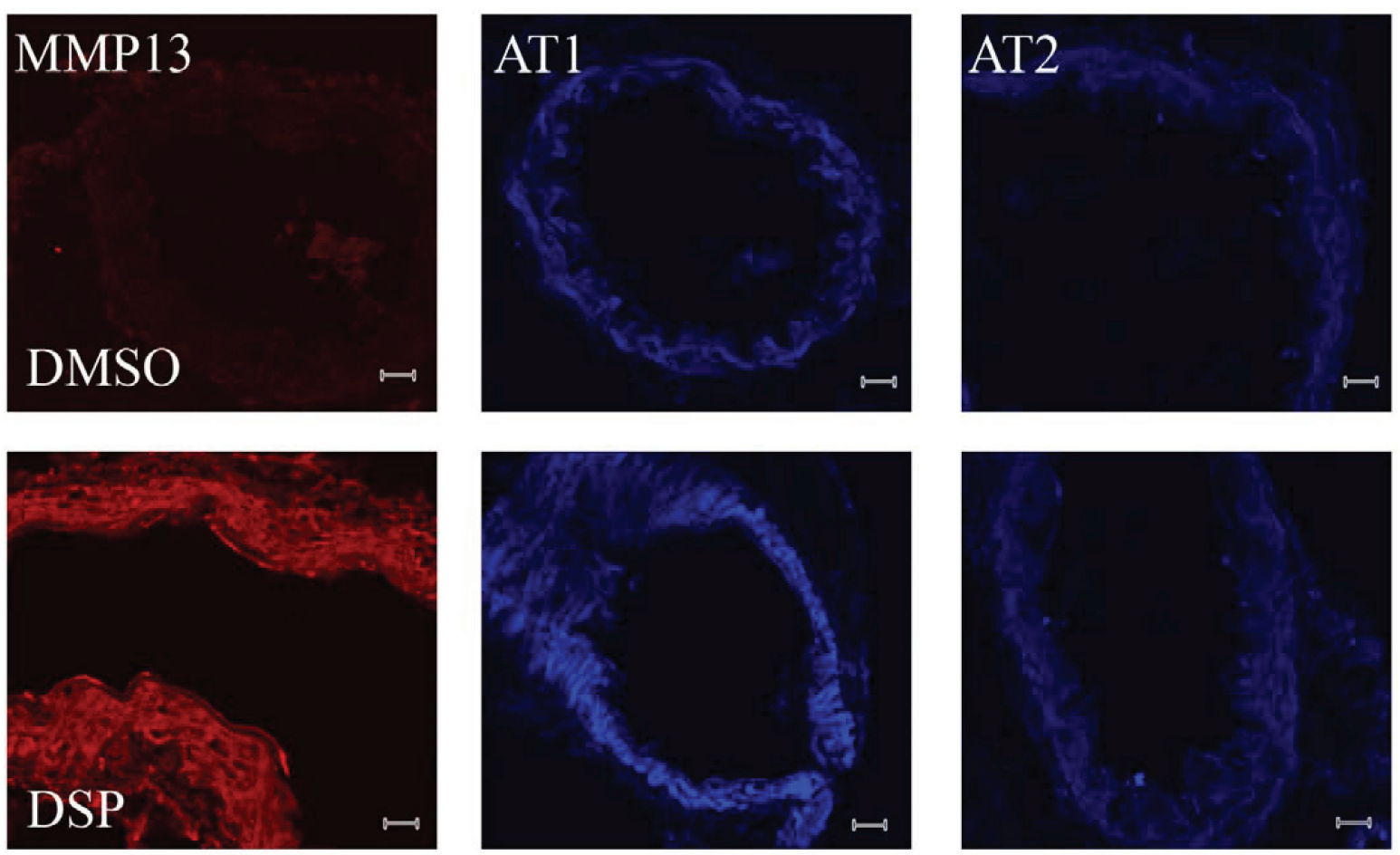

Figure 4 Immunohistochemistry shows a significant increase in the amount of phosphorylated MMPI 3 proteins and AT, receptor proteins in the cerebral arteries treated with DSP, compared with the control (DMSO-treated cerebral arteries). However, there was no increase in AT 2 receptor proteins induced by DSP. Notes: The size marker represents $20 \mu \mathrm{m}$.

Abbreviations: AT, angiotensin receptor; DMSO, dimethyl sulfoxide; DSP, cigarette smoke particles; MMP, matrix metalloproteinase. 
nicotine per se, increase the gene expression for G-protein coupled receptors in the arterial smooth muscle cells ${ }^{16,22}$ as well as induce damage of the endothelium and its functions. ${ }^{31}$ $\mathrm{AT}_{1}$ receptors mediate strong contraction of arteries and involve in vascular inflammation..$^{32}$ The enhanced expression of $\mathrm{AT}_{1}$ receptors occurs in the cerebral arteries from experimental ischemic stroke, and inhibition of the enhanced $\mathrm{AT}_{1}$ receptor expression results in reduction of the infarct volume. ${ }^{33}$ Sustained blockade of $\mathrm{AT}_{1}$ receptors with peripheral and centrally active $\mathrm{AT}_{1}$ receptor antagonists reverses the pathological hypertrophy and cerebrovascular inflammation in spontaneously hypertensive rats. ${ }^{34}$ In the present study, DSP enhanced the expression of $\mathrm{AT}_{1}$ receptors in the smooth muscle cells of the cerebral arteries. This suggests a role of $\mathrm{AT}_{1}$ receptor overexpression that might be involved in cerebral inflammation and dysfunction in smokers.

\section{Acknowledgments}

This study was supported by the Swedish Heart-Lung Foundation (grant no 20070273), the Swedish Research Council (5958), and the Flight Attendant Medical Research Institute (FAMRI, USA). The authors report no conflicts of interest in this work.

\section{References}

1. Mannami T, Iso H, Baba S, et al. Cigarette smoking and risk of stroke and its subtypes among middle-aged Japanese men and women: the JPHC Study Cohort I. Stroke. 2004;35:1248-1253.

2. Qureshi AI, Suri MF, Kirmani JF, Divani AA. Cigarette smoking among spouses: another risk factor for stroke in women. Stroke. 2005;36: e74-e76.

3. Anderson CS, Feigin V, Bennett D, Lin RB, Hankey G, Jamrozik K; Australasian Cooperative Research on Subarachnoid Hemorrhage Study (ACROSS) Group. Active and passive smoking and the risk of subarachnoid hemorrhage: an international population-based case-control study. Stroke. 2004;35:633-637.

4. Wilhelmsen L, Svardsudd K, Korsan-Bengtsen K, Larsson B, Welin L, Tibblin G. Fibrinogen as a risk factor for stroke and myocardial infarction. N Engl J Med. 1984;311:501-505.

5. Terres W, Weber K, Kupper W, Bleifeld W. Age, cardiovascular risk factors and coronary heart disease as determinants of platelet function in men. A multivariate approach. Thromb Res. 1991;62:649-661.

6. Newby DE, Wright RA, Labinjoh C, et al. Endothelial dysfunction, impaired endogenous fibrinolysis, and cigarette smoking: a mechanism for arterial thrombosis and myocardial infarction. Circulation. 1999;99:1411-1415.

7. Rogers RL, Meyer JS, Judd BW, Mortel KF. Abstention from cigarette smoking improves cerebral perfusion among elderly chronic smokers. JAMA. 1985;253:2970-2974.

8. Suh SJ, Kim JR, Jin UH, et al. Deoxypodophyllotoxin, flavolignan, from Anthriscus sylvestris Hoffm. inhibits migration and MMP-9 via MAPK pathways in TNF-alpha-induced HASMC. Vascul Pharmacol. 2008;Oct 31. [Epub ahead of print]

9. Maddahi A, Edvinsson L. Enhanced expressions of microvascular smooth muscle receptors after focal cerebral ischemia occur via the MAPK MEK/ERK pathway. BMC Neurosci. 2008;9:85.
10. Vikman P, Beg S, Khurana T, Hansen-Schwartz J, Edvinsson L. Gene expression and molecular changes in cerebral arteries following subarachnoid hemorrhage in the rat. J Neurosurg. 2006;105:438-444.

11. Stenman E, Malmsjo M, Uddman E, Gido G, Wieloch T, Edvinsson L. Cerebral ischemia upregulates vascular endothelin ET(B) receptors in rat. Stroke. 2002;33:2311-2316.

12. Stenman E, Edvinsson L. Cerebral ischemia enhances vascular angiotensin AT1 receptor-mediated contraction in rats. Stroke. 2004;35: 970-974.

13. Hansen-Schwartz J, Hoel NL, Zhou M, Xu CB, Svendgaard NA, Edvinsson L. Subarachnoid hemorrhage enhances endothelin receptor expression and function in rat cerebral arteries. Neurosurgery. 2003;52:1188-1194.

14. Hansen-Schwartz J, Hoel NL, Xu CB, Svendgaard NA, Edvinsson L. Subarachnoid hemorrhage-induced upregulation of the 5-HT1B receptor in cerebral arteries in rats. J Neurosurg. 2003;99:115-120.

15. Henriksson $\mathrm{M}, \mathrm{Xu} \mathrm{CB}$, Edvinsson L. Importance of ERK $1 / 2$ in upregulation of endothelin type B receptors in cerebral arteries. $\mathrm{Br} J$ Pharmacol. 2004;142:1155-1161.

16. Xu CB, Zheng JP, Zhang W, Zhang Y, Edvinsson L. Lipid-soluble smoke particles upregulate vascular smooth muscle ETB receptors via activation of mitogen-activating protein kinases and NF-kappaB pathways. Toxicol Sci. 2008;106:546-555.

17. Grandström BW, Xu CB, Nilsson E, Vikman P, Edvinsson L. Smoking particles enhance endothelin $\mathrm{A}$ and endothelin $\mathrm{B}$ receptor-mediated contractions by enhancing translation in rat bronchi. Bmc pulm med. 2006;6:6.

18. Russell MA, Jarvis M, Iyer R, Feyerabend C. Relation of nicotine yield of cigarettes to blood nicotine concentrations in smokers. $\mathrm{Br} \mathrm{Med} \mathrm{J}$. 1980;280:972-976.

19. Hansen-Schwartz J, Svensson CL, Xu CB, Edvinsson L. protein kinase mediated upregulation of endothelin $\mathrm{A}$, endothelin $\mathrm{B}$ and 5-hydroxytryptamine IB/ID receptors during organ culture in rat basilar artery. Br J Pharmacol. 2002;137:118-126.

20. Vikman P, Ansar S, Edvinsson L. Transcriptional regulation of inflammatory and extracellular matrix-regulating genes in cerebral arteries following experimental subarachnoid hemorrhage in rats. Laboratory investigation. J Neurosurg. 2007;107:1015-1022.

21. Vikman P, Edvinsson L. Gene expression profiling in the human middle cerebral artery after cerebral ischemia. Eur J Neurol. 2006;13: 1324-1332.

22. Zhang W, Zhang Y, Edvinsson L, Xu CB. Up-regulation of thromboxane A2 receptor expression by lipid soluble smoking particles through post-transcriptional mechanisms. Atherosclerosis. 2008;196: 608-616.

23. Low B, Liang M, Fu J. p38 mitogen-activated protein kinase mediates sidestream cigarette smoke-induced endothelial permeability. J Pharmacol Sci. 2007;104:225-231.

24. Park YS, Taniguchi N. Acrolein induces inflammatory response underlying endothelial dysfunction: a risk factor for atherosclerosis. Ann N Y Acad Sci. 2008;1126:185-189.

25. Jayaraman T, Paget A, Shin YS, et al. TNF-alpha-mediated inflammation in cerebral aneurysms: a potential link to growth and rupture. Vasc Health Risk Manag. 2008;4:805-817.

26. Horstmann S, Su Y, Koziol J, Meyding-Lamade U, Nagel S, Wagner S. MMP-2 and MMP-9 levels in peripheral blood after subarachnoid hemorrhage. J Neurol Sci. 2006;251:82-86.

27. Gaetani P, Rodriguez y Baena R, Tartara F, et al. Metalloproteases and intracranial vascular lesions. Neurol Res. 1999;21:385-390.

28. Gidday JM, Gasche YG, Copin JC, et al. Leukocyte-derived matrix metalloproteinase-9 mediates blood-brain barrier breakdown and is proinflammatory after transient focal cerebral ischemia. Am J Physiol Heart Circ Physiol. 2005;289:H558-H568.

29. Sehba FA, Mostafa G, Knopman J, Friedrich Jr. V, Bederson JB. Acute alterations in microvascular basal lamina after subarachnoid hemorrhage. J Neurosurg. 2004;101:633-640. 
30. Hartenstein B, Dittrich BT, Stickens D, et al. Epidermal development and wound healing in matrix metalloproteinase 13-deficient mice. J Invest Dermatol. 2006;126:486-496.

31. Zhang JY, Cao YX, Xu CB, Edvinsson L. Lipid-soluble smoke particles damage endothelial cells and reduce endothelium-dependent dilatation in rat and man. BMC Cardiovasc Disord. 2006;6:3.

32. Saavedra JM, Benicky J, Zhou J. Mechanisms of the anti-ischemic effect of angiotensin II AT( 1 ) receptor antagonists in the brain. Cell Mol Neurobiol. 2006;26:1099-1111.
33. Edvinsson L. Cerebrovascular angiotensin AT1 receptor regulation in cerebral ischemia. Trends Cardiovasc Med. 2008;18:98-103.

34. Ando H, Zhou J, Macova M, Imboden H, Saavedra JM. Angiotensin II AT1 receptor blockade reverses pathological hypertrophy and inflammation in brain microvessels of spontaneously hypertensive rats. Stroke. 2004;35:1726-1731. 
